\title{
Impact of Psychoanalysis in Nigeria: A Case Study
}

\author{
Ebigbo Peter Onyekwere', Elekwachi Chimezie Lekwas ${ }^{2}$, Nweze Felix \\ Chukwunenyem $^{2}$, Nwogwugwu Amara Onyinye ${ }^{2}$, and Okeke Nneka ${ }^{2}$ \\ (Enugu, Nigeria)
}

\begin{abstract}
The authors set out to examine the impact of Psychoanalysis in Nigeria. In doing this they selected a significant stakeholder, who trained in Germany and returned to Nigeria as a case study. Examining the activities as he set out to indigenize psychotherapy in Nigeria, it was found that psychoanalytic thinking helped in the psychodynamic observations on the frequent somatic complaints of psychological origin which helped to make treatment possible. Family therapy based on psychoanalysis was modeled to treat patients classified as traditional, mixed and westernized. Dream analysis and hypnosis were also used for treatment in Nigeria with good results. Finally the harmony restoration theory was put forward whereby the African is healthy when he is at peace with his world of relationship (cosmos) comprising endocosmos - mind body relationship, mesocosmos relationship with significant others and exocosmos relationship with spirits, ancestors, deities, gods, God. He/she is sick when there is a distortion in the person's world of relationship. Treatment is restoration of harmony. In every one there is a yearning to reach out to others (cosmic expansion drive) and an inclination to be interested in the self (cosmic reduction drive) at the various levels of the cosmos. Eight personality types were worked out of the combination of expansion and reduction drives. The conclusion was that psychoanalysis has come to stay in Nigeria.
\end{abstract}

Keywords: psychoanalysis, Harmony Restoration Therapy, wawa technique, indigenization, psychotherapy, somatization

\section{Introduction}

There are many possible ways to choose in reviewing the impact of psychoanalysis in Nigeria. A possible way is to sample centres of learning and practices of mental health and interview notable practitioners, or one can also do an exhaust- 
ive review of literature reflecting published works in the field of psychology and examine the impact of psychoanalysis in Nigeria.

Peter O. Ebigbo will be used as a case study to review the impact of psychoanalysis in Nigeria since 1977, the year of his return back to Nigeria from Germany where he studied Psychology at the Maximilian Bavarian University of Wuerzburg.

There will be no attempt to review psychoanalysis here beyond the basic widely known general principles as laid down by Sigmund Freud (1895-1905).

We mean the theory of the unconscious, which says that parts of our behavior and experience remain latent to us and although they are latent (latency axiom), they continue to influence our lives (manifestation axiom) and that human destiny is already written through intervention of disposition and environment virtually in the $1^{\text {st }} 6$ years of life (genetic axiom).

Out of these principles emanating from the theory of the unconscious Freud formulated the structure of the personality, first the basic unconscious part in which demands for gratification of basic needs (id) continue to be made, then the conscious part (ego) censoring the demands from the id and ensuring they are in tandem with the norms and laws of society, first, in the environment and later internalized as conscience (super ego). The ego develops various mechanisms to play its middle man's role, among others the defence mechanisms including repression, projection, transference, reaction formation etc. The unconscious has various levels ranging from full unconsciousness through preconsciousness to full consciousness. Even at the level of full consciousness, conflicts, between conscience (super ego) and instinct (id) which are embarrassing to the ego are avoided (fear). There are various levels of avoidance - from unconsciousness (e.g. dream level through, condensation of events, shifting the accent and symbolization of meaning) to the preconscious level (through slip of tongue, creative forgetfulness and parapraxis among others).

Psychoanalysis therefore is the uncovering of unconscious, sick-making conflicts and making them aware to the individual so that he/she can consciously resolve the conflict (pressure of decision between two equal and incompatible tendencies). This is because once a decision is taken, a conflict is resolved and once the conflict is resolved the fear of it and its various cloakings fissle away (healing). We will not go deeper into the oedipus conflict, its genesis and consequences and numerous other basic characteristics of psychoanalysis.

While psychoanalysis has been widely practiced and taught to students in psychiatry, psychology and other specialties in mental health in Nigeria, it has experienced some variations particularly due to culture. Psychoanalysis has also 
influenced the formation of other theories to match the Nigerian culture. Western culture, upon which psychoanalysis was based fosters, individualism, while the African culture is more collective (Mbiti, 1970). The story being narrated here is an effort to navigate around this cultural difference while still applying psychoanalytic principles.

This paper will focus on presenting various efforts to apply psychoanalysis in Nigeria and will be based on the experiences of the lead author while trying to indigenize psychoanalytic principles in Nigeria (Ebigbo, 2012).

Experience drawn from the International Federation for Psychotherapy (IFP) Centre, a community-based psychotherapy centre which was initially funded by Maria Louise Sultzer, a Swiss child psychoanalyst of the Pro Anima Foundation with the primary aim of indigenizing psychotherapy in Nigeria (Ebigbo et al., 2008), will also be made use of here.

\section{Indigenization of Universal Principles}

Indeed there is a psychic unity of mankind (Kroeber, 1981), but the various languages and cultures make it imperative that an indigenization of universal knowledge be undertaken (Ebigbo et al., 1989). It can only be so that people's mentality, belief systems, culture and indeed habit should be considered before a psychological test is developed, a psychotherapeutic method is formulated and even research undertaken (Ebigbo, 1982).

A fusion of western and local cultures has influenced mental health services in Nigeria. This fusion led Ebigbo and Ihezue (1982) to classify Nigerians who access mental health services into three types. These are: the traditional type, the westernized type and the intermediate type.

The traditional type Nigerian tends to have lived most of his or her formative years in the village (rural environment), and may have migrated to the city relatively late in life. The cognitive system is highly analogical, magical and pictorial (Ebigbo, 1981). The traditional treatment of mental illness usually includes restraining violent and aggressive mentally ill in rooms. Concoctions made of cow's urine, tobacco brew or caustic agents are used to treat convulsions and hallucinations respectively (Boroffka, 2006). For the traditional Nigerian, using traditional healers may be preferred to visiting hospitals.

The westernized type was often born and bred in an urban environment. This person is educated, a Christian and from a monogamous family structure with also educated parents. From childhood, this person may have received treatment 
in hospitals and is accustomed to this treatment modality, never having chosen prior consultation with a traditional healer.

The intermediate or mixed type constitutes the majority of patients seen at the psychiatric hospital. The patient may either have been born or bred in the village but spent most of his/her adult working life in the city, or else was raised in a city while retaining strong social and affective ties with his village. The person is the carrier of a confused mixture of cultural systems and is liable to utilize treatment modalities derived from both. This can present therapeutic challenges both to the psychiatrist, clinical psychologist and even to the traditional healer.

Psychoanalysis has played a central role in the development of the psychotherapies that suit these various groups of Nigerians.

\section{Return to learn}

The preparedness to learn about how to apply psychology to help provides mental health services, especially psychotherapy, with a number of observations forming the background to the developed intervention strategies (Ebigbo, 1982).

In the following we describe 17 observations:

1. It was observed that Nigerians have their way of thinking, belief systems and cultural rights. The idea that the fauna and flora in the environment speak and have to be understood in order to understand those who live in this environment was compelling. For example somebody talking to himself could be seen as somebody with a sign of heightened self-awareness and being one with the environment, whereas western psychiatrists would take the same sign as a symptom of schizophrenia. The person could be speaking to the ancestors. Or there is an Igbo adage that if the penis starts itching you too much, you have no choice but to display it outside.

2. Three groups who bear heavy burdens imposed by society were over represented among the mentally ill patients. The first were married women, followed by single males and then people from polygamous families (Ebigbo et al., 1981).

\section{Paranoia and Somatization explained}

3. It was observed that the hierarchical but close body tactile contact in child rearing leads to late discharge into adulthood, thus favorizing external locus of control and undue concentration on the skin as a very sensitive modus of communication; therefore the widespread paranoic tendencies and somatization as idioms of distress (Ebigbo, 1986; Ebigbo \& Onuorah, 
1987). The mind is the body and the body is the mind: Somatic symptoms are employed to communicate psychic distress. Diagnosis is understanding the communication contained at a preconscious level in these somatic complaints and therapy is solving the problems so communicated and so understood (making aware of the problem at the preconscious level).

\section{Oaths and Spells}

4. It was further observed that there is widespread belief in predestination and oaths sworn on life conditions, the violation of which leads to death or mental illness (Abiku, Ogba Nje, Agwu etc.) (Ebigbo, 2007).

5. Closely knit family relationship, prolonged breast feeding and autocratic family structures are the background for some of the conditions associated with psychopathology such as evil eye, curse, breach of oath to shrines and gods, jealousy of fellow citizens and relations (Ebigbo, 1996). The conscious and unconscious conflicts that followed these psychopathic conditions became an object of study. For example delayed self-other differentiation, late achievement of adulthood were interpreted to form the basis of libidinal cathexis of the skin, external locus of control and external attribution of guilt, which are often found among Nigerians (Staewen, 1991).

\section{Harmony is Health, Disharmony is Illness}

6. Living together with fellow humans is essential and health is having peaceful relationships with family and friends and disharmony with one's world leads to illness (Ebigbo et al., 1995).

\section{Spirits}

7. It was observed that there was widespread belief in spirits or collective power. God is the absolute spirit who handed down spirits to the various gods, such as thunder, harvest, sun etc. Then there is spirit handed down to the ancestors, from these to the eldest and/or the traditional ruler and spirits in the fauna and flora. Spirits can be peaceful and useful if their terms are kept and destructive if not. The demands of these extended forces or spirits are half internalized as conscience (super ego) and half sustained by external forces, that is, fears of sanctions when the rules of the spirits are broken. 


\section{Holistic Thinking}

8. The thinking here was holistic and no line was drawn between living and non-living, natural and supernatural, material and mental, conscious and unconscious (Lambo, 1964); all these polarities fuse into one holistic entity. Everything exists in a dynamic interrelationship, the seen and the unseen, past and present and future merge in harmony. For these people the world is the same in dream at night as in the awake state at daytime. In this manner there is a steady relationship between the dead and the living. If something unpleasant happens, there are myriads of natural and supernatural reasons for it (Ebigbo, 1984).

\section{Consequences of Arranged Marriages of Underage Girls}

9. Another observation based on clinical experience was on 20 women, who had been given into marriage at an underage period (9-13) and who now had all kinds of somatic complaints. Each one's first sexual relationship with their husbands was traumatic. An observation of two types was made. The first observation was that if a positive reaction followed the first traumatic sexual experience, a kind of imprinting fixation of the girl on the man occurred. She attained satisfaction and recognition with him. If however the man died later on or sent her away there was a disorientation and inability to have sex with another man. This was when they came to the clinic. If the reaction is negative the girl will react with frequent pregnancies, which she uses to limit the frequency of sexual intercourse as soon as she becomes pregnant. If at any time she wants to stop being pregnant, she develops symptoms such as crawling sensation, constant headache etc. to prevent future sexual intercourse. Once this was understood, treatment became easy (Ebigbo, 1979).

10. Going through hundreds of case notes of psychiatric patients at the Enugu Psychiatric hospital, it was observed that somatic complaints such as heat in the head and body, weight sensation in the head and body, dizziness, palpitations, blurred vision, weakness in memory etc. were widespread.

\section{Uncertainty in the use of Western Diagnostic Categories}

11. When this body of somatic complaints was combined, for example, with hearing of voices, the diagnosis was schizophrenia, if combined with feeling of insufficiency, it was labelled as depression etc. In addition only one third of the cases treated had a sure diagnostic label. This gave the impression 
that there was uncertainty in the use of western diagnostic illness categories for labeling mental illness in Nigeria. This led the lead author to reduce over-classification using the diagnostic categorizing and resort to listening and observing carefully what the mentally ill people were saying with their bodies (Ebigbo, \& Ihezue, 1981).

\section{Idioms of Distress}

12. As soon as this was understood, it was possible to propose that heat in the head, which led to other somatic complaints, indicated goal frustration conflict. It was also observed that sexual conflicts in connection with a recent traumatic event were accompanied by complaints of a wormlike crawling sensation in the body. Two types of crawling sensations were observed, one is wormlike crawling mainly in the body associated with sexual ambivalence and the other is a ant like crawling sensation under the body skin or inside the head associated with perceived unbearable social and family demands (brain-fag). The feeling of heaviness in the head and shoulder indicated an ambivalent sense of responsibility (especially financial in nature), a burden which a person symbolically carried. If all the symptom groups appear together, they could attract a fourth symptom such as internal heat. Both internal heat and biting sensation all over the body show alarm states of the patient. A lot of such meaning, were gathered enabling quick translation of idioms of distress into social and psychological problems. The patients are helped to solve these problems if possible, or helped to accept if not possible to solve. Both scenarios mean healing (Ebigbo, 1982; Ebigbo, 1983 a, b; Ebigbo, 1996).

We see this as a miniature awareness-making of the sick making conflict virtually hidden at the preconscious level.

\section{Traditional healers}

13. It was also observed that there were others, who were doing the same work as a clinical psychologist within the society, namely the traditional healers and the prayer house priests. To know their methods and to possibly draw from their healing methods was especially important to us. As already mentioned, the traditional healers were here seen as mediators between gods, spirits and human beings. They claim to recognize the messages of the supernatural and to find possibilities for the treatment of human beings through them. Traditional healers possess above average-knowledge of 
humans and have deep insight into the native cultures, beliefs, rituals and customs.

\section{Prayer houses}

It was observed that in the prayer houses especially the senses were aimed at in order to increase the power of expression. Colours and symbols played an important role as well as the scent of incense. Patients would sing and dance until they saw visions (a sort of cathartic projection in a sort of trance - like state) and began to confess how to improve their life style in a sing-song. Monotonous prayers have a relaxing effect on the participants. Artificial enemies or evil spirits are made responsible for the illness. At the same time they are fought against with God's help and power. The participants quickly become a group in which members help one another. Of course the clients experienced temporary relief. In creating new pathologies and healing them with temporary relief, they created a dependency that makes their clients members of their church on a permanent basis (Ebigbo \& Tyodzua, 1980).

\section{Vagrant Psychotic's Healers}

In Nigeria, besides traditional healers there is also a group of wandering healers. They go to town and literarily capture mentally ill people, who are called "vagrant psychotics." They transport them into an empty house, give them a lot of food to eat and pray with them. Already at dawn they wander in a row through town beating rhythmically on plates and other improvised musical instruments as they march along the streets begging for money.

In this manner they wander the whole day and collect money. In the evening they return to the empty house totally exhausted. Again they get a large portion of food and a sort of drink concoction got from the bark of a tree (e.g. Rawolfia) which has a sedating effect. The social relationship created by the action of this group appears to have a favourable effect on these patients. Similarly the daily wandering and the consequent bodily exhaustion seems to have a useful effect as a therapeutic method. These "healers" who captured their patients by force appear to have very strong personalities (Ebigbo, 1989). Psychoanalytic phenomena such as identification, projection, suggestibility, catharsis were studied to try to explain the healing methods in order to learn from them. 


\section{The Treatment Challenge}

But how did the treatment method of the psychoanalytically oriented clinical psychologist trained in Europe look like? Patients who described their complaints through bodily symptoms came from far and expected ready-made help like from the traditional healers through injections and tablets. They were accustomed to getting a clear diagnosis, medicine and special instructions. Emotional conflicts were expressed physically and treatment was expected to be physical too, even if it was water, blessed oil/ointment, prayer through laying on of hands, an injection, tablets and/or a concoction. There is a proverb here that medicine that is not painful cannot heal a wound, emphasizing that medicine must be tangible and therefore felt in order to heal by impact of bodily touching on illness and healing.

Psychoanalysis, if not stepped-down or indigenized, is considered foreign to Nigerians. However, most people in the same community easily believe one another and they already know about dream interpretation from traditional healers. Therefore, the use of hypnosis and dream interpretation became promising. Once the clinical psychologist succeeded with hypnotic treatment, the patient was ready to consider collecting his/her dreams and to be helped to interpret them. This was seen as an alternative to drug treatment, which often failed to help when used exclusively. Dream analysis proved therefore to be point of entry into psychotherapy.

\section{Hypnosis}

The experience here in Nigeria was that one had to speak with the patient before and after hypnosis to clear doubts and answer questions. Some patients would otherwise call the hypnotist a magician. Patients wanted something concrete. They liked it to be directed into the healing process, wanted to be able to classify a therapist into herbalist (healers, who use drugs) or traditional healer (healer without drugs, who used incantations or invocations to heal). The hypnotist was seen to be more like a traditional healer. Hypnosis and suggestion were so effective in Nigeria that some people made it their stock-in-trade to hypnotize people on the streets, in taxis, in churches and then extort money, trinkets, or electronic equipment from them. These people first claim to be great prophets, healers, religious leaders, people from beyond etc. They get into contact with their prey, make a few tests of suggestibility and put their clients in trance before commanding them to go home to bring money supposedly necessary to carry out rituals for their benefits; they promise to pray for them, to double their money, to heal their sick and avert evil from them and their relatives. This suggestibility of Nigerians was 
to be utilized therapeutically (Ebigbo, 1989). This has led to the use of hypnosis and relaxation training for patients at the University of Nigeria Teaching Hospital Enugu, a programme captioned Stress Innoculation Programme (Ebigbo, 1986). The experience was a successful one. The autogenic relaxation method modeled after Schulz (1932) and the programme of progressive muscle relaxation according to Jakobson 1948 were also quite effective.

The initial goal of therapy of somatic complaints was to make it clear to the patient that he/she was not bodily ill. Otherwise, he/she would not accept psychotherapy. Also patients were sent to other medical doctors or to laboratory tests, where it was confirmed that the patient had no organic illness.

\section{Essays as Prelude to Guided Affective Imagery}

It often happened that patients, realizing they were bodily alright, lost their symptoms or produced others. In such a situation patients were encouraged to write essays. The topics were the persons' autobiography, "the story of my life" or "my present situation," or "the story of my mental illness." This was used as an attempt to awaken consciousness of their personal problems. Later the essays were read back to the patients in a hypnagogic state for the purpose of re-experience. Such situations were exploited therapeutically by making use of the ability for phantasy and imagination of the patients. We also wanted to incite their readiness to subjugate themselves to a procedure they did not understand, based on trust, and to accept interpretations of symbols and images. The reading of the written topics to the patients helped animate them to bring forward remembrances, experiences, fears and hopes, real and unreal possibilities of solving their problems. The therapist understood and interpreted the produced materials.

Other topics were "how can I overcome my emotional problems," "why do I believe that my situation is not so bad," "how I used to help myself." Patients were encouraged to describe very concretely their states after recovery, also to write down their dreams which were read back to them later, requesting new dreams at each meeting. Remembrances and interpretations were digested. The traditional method of guided affective imagery according to Leuner (1964) was also successfully applied among the people, only that we had to replace the European standard motives such as meadow or edge of the wood with other motives which corresponded to Nigerian symbols like house, river, moon light, festival, masquerade etc., Psychodrama and family therapy have proved to be very useful likewise. 


\section{Group Therapy}

An analytic model was developed which, simplified, could be reduced to two parts.

, The first phase was that of interaction, getting acquainted, of inter-personal interaction and group formation. Traditional interaction methods such as singing, dancing and other rituals were made use of.

, The second phase was that of analysis, of digesting of problems and of presenting possibilities for the solution of the conflict. For the Nigerian group therapist it was especially important to be flexible and full of ideas, to master as many therapy methods as possible and to apply them to each corresponding case. But the basic thing here is to create trust and remove inhibition (awareness making of latent pathogenic conflicts).

\section{Native Judgment model for polygamous families}

14. Usually when a person from a polygamous family feels he or she has been wronged, he/she proceeds first to the eldest man in the family. For example a wife who has been wronged brings kola nuts and a fowl to the eldest, reporting the wrong-doing of the husband. The eldest calls a family meeting and both parties are heard by the family "court" and a judgment passed. We made attempts to incorporate parts of this judgment system in the family therapy model. The therapist was the key member. The extended audience replacing the extended family comprised hospital staff, psychologists, doctors, nurses, social workers, etc. All sat down in a circle or semi-circle just like in the native judgment method. The therapist tried to verbalize the problem. Key members of the disturbed polygamous family were invited, for example parents, a brother or a sister. Each got a chance to mention his/ her present needs and motives (Schmidt, 1975; Toman, 1973). The audience listened and helped the individual family members to present their problems and act them out. Members of the audience based their support freely on sympathy, empathy, identification, transference etc. After the first stage of acting out came the phase of self-reflection, in which one searched for older motives and needs (Beese, 1992; Overbeck, 1979; Schmidt, 1975; Sperling, 1972, etc.), that could be responsible for the sick-making role delegation (Richter, 1968) or narcissistic transference relationship (Overbeck, 1979). In these sessions, which at one time had the character of a group therapy and at another time, the character of a family therapy, there were no winners or losers. The therapist, seen as a judge or head of family at the beginning, lost this 
role in the process of therapy and became one who understood and helped (Ebigbo, Onyeama, Ihezue \& Ahanaotu, 1981).

\section{Family Therapy with Monogamous Nigerian Families}

The westernized type and some mixed Nigerians found the native judgment model too autocratic. For these we adopted the family therapy model of Schmidt (1975), who described four ideal process stages of a family therapy, although he warned that these were not sharply distinct from one another.

In the first phase, the family members speak about their conflicts, each one highlighting the things of which he has been deprived. The theme is: "What is wrong at the moment?" In the second phase, the family talks about the history of the conflicts and discovers earlier connections between the main motives. The theme is: "How did the conflicts arise?" The therapist tries to work out the connections between the main (earlier) and constant (present) motives. In the third phase, the members of the family, especially the parents, learn more about the connections between their individual basic, earlier or main conflicts (in their parental homes) and their present (within the marriage) constant motives, as well as the motives of the children. The theme is: "What are my/our real problems?" The therapist can be of help here. In the fourth phase, the family members learn more about their individual wishes and expectations and their background. The theme is: "What can we do in the future?" A new modus vivendi is sought that will make family members more satisfied (Ebigbo, Onyeama, Nkemena \& Ahanotu, 1982).

Very importantly, in this process we try to break the vicious circle of obsessive repetition of the parent's childhood in their children. In the family therapeutic transference situation, parents can verbalize their childhood misery and consciously experience the anger and sorrow that they were forced to suppress. In this manner they reconcile with their own parents so that present-parent child relationship, characterized by acceptance and partnership, can evolve.

\section{Family Therapy in Paediatric Practice}

Pediatricians often referred cases of childhood psychopathology to our psychological clinic. We were aware that the symptoms of children could not be understood or treated without recourse to the family. Therefore family therapy for treatment of children's emotional problems was adapted (Ebigbo, 1983; Ebigbo \& Izuora, 1984). Here the family collusion model according to Willi $(1975,1978)$ as exposed by Buddenberg (1982) was adopted. According to Willi, collusion means a common way of behavior unaccepted and hidden from one another by two or 
more partners because they have similar and undigested basic conflicts. There are principles of functioning which determine whether disturbances in the relationship or symptom formation appear in disturbed families. Three principles of functioning determine a family's common way of behavior (Ebigbo \& Izuora, 1984).

, The ability of the family to withstand environmental influences and contacts.

, The second principle of functioning relates to the family's ability to adapt to maturational processes, e.g. pregnancy, birth, separation, illness, death etc. (Bibring, Dwyer, Huntington \& Valensten, 1961).

> The third principle relates to social contingency, which refers to the way and manner a family entertains contact with other social groups. It can react with adaptation or rejection of the norms of these groups.

The goal of family therapy is therefore to discover the way a family functions and the rules that govern that way of functioning, especially in disturbed families, who always present a certain paradox. This consists in that on the one hand they want to understand and explain their problems and on the other hand they frustrate efforts leading to that explanation and understanding. In the case of very disturbed families the relevance and existence of these problems may be denied completely.

Analytic oriented family therapy was also used to prepare clients for death (Ebigbo, 1985). Quality of dying just like quality of life is the goal here.

\section{Wawa Techniques}

15. In treating cases of drug addiction, people with a weak ego or a very weak will power needed a well-grounded method to help them keep away from drugs. The method designed for these cases was based on using cultural methods to rehearse the moral order (wawa-technique) and saying "No" to its contravention.

The rehearsing is continued at home and anytime the temptation is felt. Wawa technique creates a dissonance within one's cognitive structure and invites the person to change his attitude or behaviour to establish consonance (Festinger, 1957). The moral yard stick is the internalized collective norms and mores developed and internalized over years of living together.

A similar method was developed by Awaritefe, namely the Meseron Therapy, Meseron meaning "I reject it." His method and explanation go in the direction of the cognitive behaviour therapy of Ellis (Ofovwe \& Awaretafe, 2008). In the wawa technique the moral order is established though breaking of kola nuts and the use of idioms, declaration of the behaviour in question e.g. drug abuse and inviting 
the person to reject it, to spit on it, to loathe it and deny to the ancestors that one is part of it and to continue doing it until it clicks (Ebigbo, Elekwachi \& Nweze, 2012).

\section{Types of Dreams}

16. Dreams mean a lot to Nigerians and there are people who claim to interpret dreams. Different theories were put forward as to what dreams mean. Some believe that what they dream about will happen. If they dream somebody died, that person will die, if they dream of eating food they will become rich etc. The dream contents of 30 psychiatric patients from the Enugu Psychiatric Hospital, now Federal Neuropsychiatric Hospital Enugu, were studied. The dreams were classified into broad types, resulting in two main types of dreams namely fearful dreams and dreams of sexual nature. In order to determine whether or not people with similar complaints have similar dreams, the patients were classified into two main categories according to their complaints, namely crawling sensation and headache patients. Patients who complained of crawling sensation tended to have more sexual dreams while patients with headache had more fearful dreams. Those who complained of crawling sensations tended to be unsure, shy, withdrawn and to have weak ego personalities. No particular trend was found among headache patients. Means of assessment was systematic psychological exploration.

Furthermore, patients who complained of crawling sensation and who had sexual dream contents tended to be over 28 years old and had an unsatisfactory sexual life.

\section{Dream contents of Nigerians}

Another observational study was the collection of the dreams of 74 students of the University of Nigeria Enugu Campus. This revealed that (Ebigbo, Onyeama, \& Nkemena, Family Therapy with Polygamous Nigerian Families, 1982) the students in this study were very much preoccupied with family and natural phenomenon. Many of them believed that dreams could forecast events. The more educated they were, the stronger was the tendency to believe that dreams were a reflection of the awake state and sort of a stage to act out unconscious drives, fulfill repressed wishes, compensate insufficiencies both directly and symbolically, help the brain to get rid of excessive and unused stimuli coded during the day, etc. The extended family system, material needs, fear of robbery, sexuality, religion and interpersonal relationship form the main dream contents of the interviewed 
subjects. The Nigerian, as seen in this study, seemed to use death, blood, pursuit by dangerous animals, (snakes and reptiles), mermaids, evil spirits, masquerades, etc. to symbolize his/her fear. Sometimes wishes were satisfied in the negative. Instead of dreaming that a brother lived long, as he/she would wish, the Nigerian would sometimes dream that his/her brother or sister was dead.

Natural phenomena like darkness, unknown destination, a lonely road or a deserted house covered by thick woods are used as a prelude to fearful incidents. Most of the dreams have one or another fear element, and when the dreamers feared something, that thing pursued them in the dream (Ebigbo, 1982). In Nigeria no one dies without people saying he was poisoned or that someone was responsible. This has important implications for the treatment of manic, phobic and schizophrenic illnesses and especially paranoid delusion cases in our psychiatric hospitals.

It was tempting to hypothesize, though without experimental evidence, that the Nigerian generally tends to a manic exposition and paranoid translation of events. This in contrast to the more depressive and obsessive translation of event, by the European, (Ebigbo, 2001).

\section{Harmony Restoration Therapy}

17. Having studied several cultures and belief systems, in Nigeria it was noted that the Nigerian has an internal yearning to reach out and be at peace with his/her world. His/her world is the web of relations (cosmos) he/she entertains in him/herself - mind and body (endocosmos), between him/ her and his/her fellow humans (mesocosmos), between him/her and his/ her ancestors, spirits, gods, God and the supernatural (exocosmos). He/ she is at peace and healthy if there is harmony in his/her world (cosmos) comprising of endocosmos, mesocosmos and exocosmos. The yearning to reach out and be at peace with his/her world is the cosmos expansion drive, and in opposition to that, the drive that leads him to do things on his/her own, based on his/her needs alone, is the cosmos reduction drive (Figure 1). Harmony, peace and good health prevail when the cosmos expansion drive gains the upper hand - and illness if the cosmos reduction drive gains the upper hand, the height of which is cosmic atrophy, eventually leading to chaos and death (Ebigbo, 2008) Harmony Restoration Therapy is a therapeutic framework that determines the level of harmony/distortion in the cosmos. It shows where it is located and restores the harmony, selecting the form of therapy that is best suited for that: Communication Therapy, Family 
Therapy, Behaviour Therapy, Psycho dynamic methods, wawa technique etc. Crucial to this is the development of the harmony restoration measurement scale (Ebigbo, Elekwachi, Eze, Nweze, \& Innocent 2010).

\section{African Personality Model}

An African personality model also based on the Harmony Restoration Theory has been developed. It has three components namely the ENDOCOSMOS, the MESOCOSMOS and the EXOCOSMOS (Ebigbo, 1997, 2001). The three components have both expansion and reduction drives. The striving to be in harmony within endocosmos, mesocosmos and exocosmos is termed cosmos expansion and is motivated by a positive unconscious phenomenological aspiration. To make the individual personality be in complete harmony with his/her cosmos (world) is to be in a state of cosmos symphony. The goal of unconscious aspiration not to be in harmony with the cosmos or cosmos reduction, is to please the self (Ebigbo, 2001). Therefore, the task is to find the possible personality attributes which will fit into the eight combinations in the endocosmic, mesocosmic and exocosmic expansion and reduction drives listed below (Ebigbo, Nweze, Elekwachi \& Ezenwa, 2012).

\section{Table 18 Personality types arising from combinations of cosmic expansion and reduction drives}

\begin{tabular}{|c|c|c|}
\hline 1 & $\mathrm{ECE}+\mathrm{MCE}+\mathrm{EXCE}$ & Mind body harmony, adaptable, sociable, religious \\
\hline 2 & $\mathrm{ECE}+\mathrm{MCR}+\mathrm{EXCE}$ & Mind body harmony, not adaptable, not sociable, religious \\
\hline 3 & $\mathrm{ECE}+\mathrm{MCE}+\mathrm{EXCR}$ & Mind body harmony, adaptable, sociable, not religious \\
\hline 4 & $\mathrm{ECR}+\mathrm{MCE}+\mathrm{EXCE}$ & $\begin{array}{l}\text { Mind body disharmony, tries to be sociable, adaptable, tries to } \\
\text { be religious }\end{array}$ \\
\hline 5 & $\mathrm{ECR}+\mathrm{MCR}+\mathrm{EXCR}$ & $\begin{array}{l}\text { Mind body disharmony, not sociable not adaptable, } \\
\text { not religious }\end{array}$ \\
\hline 6 & $\mathrm{ECR}+\mathrm{MCE}+\mathrm{EXCR}$ & Mind body disharmony, sociable adaptable, not religious \\
\hline 7 & $\mathrm{ECE}+\mathrm{MCR}+\mathrm{EXCR}$ & Mind body harmony, not sociable, not adaptable, not religious \\
\hline 8 & $\mathrm{ECR}+\mathrm{MCR}+\mathrm{EXCE}$ & $\begin{array}{l}\text { Mind body disharmony, not sociable, not adaptable, tries to } \\
\text { be religious }\end{array}$ \\
\hline
\end{tabular}

Endo cosmic Expansion = $($ ECE $)$ : Mesocosmic Expansion $=($ MCE $)$ Excocosmic Expansion $=($ EXCE $)$ Endo cosmic Reduction $=($ ECR $)$ : Mesocosmic Reduction $=($ MCR $)$ Excosmic Reduction $=($ EXCR $)$.

Eight personality types deriving from combination of reduction and expansion drives in the three components of the cosmos emerged.

At the end of this review we can say that psychoanalysis has given a solid basis for understanding and interpreting idioms of distress and dreams, for under- 
standing and treating psychopathology and for formulating the harmony restoration theory, harmony restoration therapy and harmony restoration personality, which attempt to open the way to greater application of psychoanalytic psychology in clinical psychology practice in Africa. Psychoanalysis has come to stay in Nigeria.

\section{References}

Beese, F.C. (1982). Neurosenstruktur und Familiendynamik (Theoretische Grundlagen). Praxis der Kinderpsychologie und Kinderpsychiatrie, 4, 126-130.

Bibring, G. L., Dwyer, T.R, Huntington, D. S., \& Valenstein, A. F. (1961). A study of the psychological processes in pregnancy and of the earliest mother-child relationship. Psychoanalytic Study of the Child, 16, 9-72.

Buddenberg, C., \& Buddenberg, B. (1982). Family conflicts in collusion: A psychodynamic view for family therapy. Praxis der Kinderpsychologie und Kinderpsychiatrie, 4, 143-150.

Dinslage, A. (1982). Familie in der Krise. Was soll aus dem Kind werden. Psychologie Heute, 9, 31-36.

Ebigbo, P.O., Elekwachi, C.L., \& Nweze, F.C. (2014). Brain fag: New perspectives from case observations. Transcultural Psychiatry, 1-20. doi:10.1177/1363461514557064

Ebigbo, P.O., Elekwachi, C. L., \& Nweze, F.C. (2012). Challenges in the treatment of drug abuse in a Nigerian female health worker: A case study applying the Wawa technique. Journal of Contemporary Psychotherapy, 42, 257-264.

Ebigbo, P.O. (2012, November 29). Indigenization of Psychotherapy in Nigeria, a personal account. College of Medicine Retirement Valedictory Lecture. Enugu, Nigeria.

Ebigbo, P. O., Elekwachi, C.L., Eze, J.C., Nweze, F. C., \& Innocent, C. U. (2010). Development of Harmony Restoration Measurement Scale. Nigerian Journal of Clinical Psychology, 8, 25-49.

Ebigbo, P. O. (2008). Positioning Culture and Psyche of Nigerians Towards Attaining Rapid Technological and Industrial Developmental Goals for Vision 2020 through the Development of the Nigerian Measurement Scale and Nigerian Psyche Handbook. Abuja: Nigerian National Merit Award Board.

Ebigbo, P. O. (2007, August 25th). Ogba Nje phenomenon - A Psychopathological variation of the African Mind. Enugu State University of Science and Technology. Agbani, Enugu, Nigeria: Department of Psychology. 
Ebigbo, P. O. (2001). In search of the Nigerian psyche: A contribution to nation building. Enugu: Nigerian National Merit Award Board.

Ebigbo, P. O. (1996). Somatic Complaints of Nigerians. Journal of Psychology in Africa, 1, 28-49.

Ebigbo, P. O., Janakiramiah, N., \& Kumaraswamy , N. (1989). Somatization in cross cultural perspective. In K. Peltzer, \& P. O. Ebigbo (eds.), Clinical Psychology in Africa (pp. 233-250). Enugu: Chuka Press.

Ebigbo, P. O. (1989). Family therapy in pediatric practice in Nigeria. In K. Peltzer, \& P. O. Ebigbo, Clinical Psychology in Africa (pp. 551-574). Enugu: Chuka Press. Ebigbo, P. O. (1989). Participatory observation of the healing methods of a Nigerian prayer house. In K. Peltzer, \& P. O. Ebigbo, Clinical Psychology in Africa (pp. 485-489). Enugu: Chuka Press.

Ebigbo, P. O. (1989). Psychological approach to the dreams of Nigerians. In K. Peltzer, \& P.O. Ebigbo, Clinical Psychology in Africa (pp. 490-550). Enugu: Chuka Press.

Ebigbo, P. O. (1989). Stress Inoculation. Enugu: Cecta Press.

Ebigbo, P.O. (1989). The Role of hypnosis and relaxation therapies in the Management of the mentally ill. In K. Peltzer, \& P. O. Ebigbo, Clinical Psychology in Africa (pp. 620-647). Enugu: Chuka Press.

Ebigbo, P. O. (1989). Vagrant psychotic healers in Nigeria. In K. Peltzer, \& P.O. Ebigbo, Clinical Psychology in Africa (pp. 482-484). Enugu: Chuka Press.

Ebigbo, P. O., \& Onuora, A. N. (1987). Zum besseren Verständnis und zur Behandlung von Paranoia und Somatisierungserscheinungen bei Nigerianern. Zeitschrift für Psychosomatische Medizin und Psychoanalyse, 33, 78-90.

Ebigbo, P. O. (1986). The mind, body, and society: An African Perspective. ADVANCES Institute for the Advancement of Health, 4, 45-57.

Ebigbo, P. O., \& Ihezue, U.H. (1986). Psychodynamic observations of the symptom of heat in the head. African Journal of Psychiatry, 7, 25-30.

Ebigbo, P.O., Ojukwu, J., \& Ukabam, S. O. (1985). Family therapy in the management of a dying Nigerian Cancer Patient. International Journal of Family Psychiatry, 1, 83-95.

Ebigbo, P.O. (1984). Psychotherapy in Africa: Quo Vadis? Scientific Programme Committee of the Korean Academy of Psychotherapists (pp. 275-285). Seoul: International Congress on Psychotherapy East \&West.

Ebigbo, P.O. (1983a). Psychosomatic complaints of Nigerian students. Zeitschriftt für Psychosomatische Medizin und Psychoanalyse, 2, 174-184. 
Ebigbo, P. O. (1983b). Somatization in Nigeria - diagnostics and therapy. Psychosomatic Medicine and Psychotherapy, 43, 396-400.

Ebigbo, P.O., \& Ihezue, U.H. (1982). Uncertainty in the use of Western diagnostic illness categories for labeling mental illnes in Nigeria. Psychopathologie Africaine, 28:1, 59-74.

Ebigbo, P. O. (1982). Development of a culture specific (Nigeria) screening scale of somatic complaint indicating psychiatric disturbance. Culture Medicine \& Psychiatry, 6, 29-43.

Ebigbo, P. O. (1982, April). Psychotherapie in Afrika. Schwarze Kultur und Weisse Psychologie. Psychologie Heute, 4, 64-71.

Ebigbo, P. O., Onyeama, W. P., \& Nkemena, A. C. (1982). Family Therapy with Polygamous Nigerian Families. International Journal of Family Psychiatry, 3, 82-101.

Ebigbo, P.O., Onyeama, W.P., Ihezue, U.H., \&Ahanaotu, A.C. (1981). Familientherapie bei polygamen nigerianischen Familien. Zeitschrift für Psychosomatische Medizin und Psychoanalyse, 2, 180-191.

Ebigbo, P.O., \& Ihezue, U.H. (1981). Ameisenkribbeln (Crawling sensation). Kann verdrängte Sexualitaet körperliche Beschwerden verursachen? Sexualmedizin, 10, 402-404.

Ebigbo, P.O. (1981). The belief in Reincarnation (Ogba - Nje) and its meaning for Psychotherapy in Nigeria. Zeitschrift für Psychosomatische Medizin und Psychoanalyse, 27, 84-91.

Ebigbo, P. O., \& Tyodzua. (1980). “Enugu Prayer House”. Ibadan: Ibadan University Press.

Ebigbo, P.O. (1979). Arranged marriages of underage girls and their psychic consequences. Zeitschrift für psychomatische Medizin und Psychoanalyse, 4, 376-381.

Festinger, L. (1957). A theory of cognitive dissonance. Stanford: Stanford University Press.

Jackobsen, E. (1929). Progressive relaxation. Chicago: University Press.

Krober, A. I. (1981). Anthropology. New York: Harcourt Brace New York.

Leuner, K. H. (1964). Das assoziative Vorgehen im Symboldrama. Zeitschrift für Psychotherapie und medizinische Psychologie, 14, 196-211.

Mbiti, J. (1970). African religion and philosophy. New York: Anchor Books.

Miller, A. (1982). An Anfang war die Erziehung. Frankfurt: Suhrkamp.

Misslildine, W.H. (1979). In der lebt noch was. Frankfurt: Suhrkamp. 
Ofovwe, C.E., \& Awaritefe, A. (1982). Rational Emotive Therapy and Meseron. Nigerian Journal of Clinical Psychology, 6, 29-36.

Overbeck, G. (1977). Familiendynamische Perspektiven in der Untersuchung psychosomatischer Krankheiten. Praxis der Kinderpsychologie und Kinderpsychiatrie, 28.

Schmidt, R. (1975). Psychoanalytic oriented family therapy according to the duplication. Praxis der Kinderpsychologie und Kinderpsychiatrie, 7, 254-258.

Schulz, J.H. (1932). Das autogene Training (konzentrative Selbstentspannung). Versuch einer klinisch-praktischen Darstellung. Stuttgart: Thieme.

Sperling, E. (1972). Besonderheiten in der Behandling von Magersuchtfamilien. Psyche, 26, 357-369.

Staewen, C. (1991). Kulturelle und psychologische Bedingungen der Zusammenarbeit mit Afrikanern. Ansatzpunkt für eine komplementäre Partnerschaft. London, München, Köln: Weltforum.

Willi, J. (1975). Zweierbeziehung. Reinbek: Rowohlt.

Willi, J. (1978). Therapie der Zweierbeziehung . Reinbek: Rowohlt.

\section{Annotations}

1 Department of Psychological Medicine College of Medicine, University of Nigeria, Enugu Campus, peterebigbo@yahoo.com.

2 International Federation for Psychotherapy Centre (IFP) 20 Anyaegbunam Street Uwani Enugu Nigeria, chimezieelekwachi@gmail.com. 